Canadian Journal of Civil Engineering

Canadian

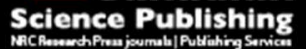

Revue canadienne de génie civil

\title{
Development of a Methodology to Backcalculate Pavement Layer Moduli Using the Traffic Speed Deflectometer
}

\begin{tabular}{|c|c|}
\hline Journal: & Canadian Journal of Civil Engineering \\
\hline Manuscript ID & cjce-2017-0570.R1 \\
\hline Manuscript Type: & Article \\
\hline Date Submitted by the Author: & 27-Dec-2017 \\
\hline Complete List of Authors: & $\begin{array}{l}\text { Elbagalati, Omar; Louisiana State University, Civil and Environmental } \\
\text { Engineering } \\
\text { Mousa, Momen; Louisiana State University College of Science } \\
\text { Elseifi, Mostafa; LSU, CEE } \\
\text { Gaspard, Kevin; Louisiana Transportation Res, Pavement Research; } \\
\text { Zhang, Zhongjie; Louisiana Transportation Research Center, }\end{array}$ \\
\hline $\begin{array}{r}\text { Is the invited manuscript for } \\
\text { consideration in a Special } \\
\text { Issue? : }\end{array}$ & N/A \\
\hline Keyword: & $\begin{array}{l}\text { traffic speed deflectometer, pavement evaluation, falling weight } \\
\text { deflectometer, pavement management }\end{array}$ \\
\hline
\end{tabular}


1 Development of a Methodology to Backcalculate Pavement Layer Moduli Using the Traffic Speed Deflectometer

\author{
Omar Elbagalati ${ }^{1}$, Momen Mousa ${ }^{2}$, Mostafa A. Elseifi ${ }^{3}$,
}

Kevin Gaspard ${ }^{4}$, Zhongjie Zhang ${ }^{5}$

7 ABSTRACT: Backcalculation analysis of pavement layer moduli is typically conducted

8 based on Falling Weight Deflectometer (FWD) measurements; however, the stationary

9 nature of FWD requires lane closure and traffic control. To overcome these limitations, a

10 number of continuous deflection devices were introduced in recent years. The objective

11 of this study was to develop a methodology to incorporate Traffic Speed Deflectometer

12 (TSD) measurements in the backcalculation analysis. To achieve this objective, TSD and

13 FWD measurements were used to train and to validate an Artificial Neural Network

14 (ANN) model that would convert TSD deflection measurements to FWD deflection

15 measurements. The ANN model showed acceptable accuracy with a coefficient of

16 determination of 0.81 and a good agreement between the backcalculated moduli from

17 FWD and TSD measurements. Evaluation of the model showed that the backcalculated

18 layer moduli from TSD could be used in pavement analysis and in structural health

19 monitoring with a reasonable level of accuracy.

\footnotetext{
${ }^{1}$ Graduate Research Assistant, Louisiana State University

${ }^{2}$ Graduate Research Assistant, Louisiana State University

${ }^{3}$ Professor, Department of Civil and Environmental Engineering, LSU.

${ }^{4}$ Senior Pavement Research Engineer, Louisiana Transportation Research Center

${ }^{5}$ Pavement Geotechnical Research Administrator, Louisiana State University
} 
20 Keywords: Traffic Speed Deflectometer, backcalculation, Falling Weight Deflectometer,

21 3D Move, deflection velocity

\section{INTRODUCTION}

23 Backcalculation of pavement layer moduli using Non-Destructive Testing (NDT)

24 measurements is a commonly accepted procedure for evaluating pavement structural

25 conditions (Saltan and Terzi 2008). Structural conditions evaluation of in-service

26 pavements is essential to estimate pavement Remaining Service Life (RSL) and to select

27 the most appropriate maintenance and rehabilitation activities (Goktepe et al. 2006).

28 Backcalculation of pavement layer moduli is also necessary to calculate pavement

29 responses under traffic loads (i.e., stresses, strains, and deflections) through both the

30 layered elastic theory and the finite element method. In addition, overlay design in the

31 new American Association of State Highway and Transportation Officials (AASHTO)

32 Pavement Mechanistic-Empirical (ME) design guide requires defining the backcalculated

33 layer moduli of in-service pavements (Haider et al. 2014). The backcalculated layer

34 moduli can also be used in structural health monitoring of in-service pavement structures

35 (Elbagalati et al. 2016).

36 The Falling Weight Deflectometer (FWD) is the most widely used NDT device

37 for evaluating the structural conditions of in-situ pavements and in conducting

38 backcalculation analysis; however, the stationary nature of the device limits its

39 production rate, which reduces its applicability at the network level (Leiva-Villacorta and

40 Timm 2013; Rada et al. 2011). The static nature of FWD disturbs traffic, requires traffic

41 control, and increases accidents risk (Flintsch et al. 2013). To overcome these

42 limitations, a number of continuous deflection measurement devices were introduced in 
43 recent years. A recent Strategic Highway Research Program 2 (SHRP2) study identified

44 the Traffic Speed Deflectometer (TSD) and the Rolling Wheel Deflectometer (RWD) as

45 the most promising continuous deflection measurement devices (Flintsch et al. 2013).

46 TSD allows the measurement of the complete deflection basin; therefore, it could be used

47 in backcalculation analysis (Muller and Roberts 2013).

\section{OBJECTIVES}

49 The objective of this study was to develop a methodology to incorporate TSD

50 measurements in the backcalculation analysis of flexible pavements. TSD and FWD

51 measurements were obtained from two testing programs conducted in District 05 of

52 Louisiana and at the MnROAD test facility in Minnesota. These measurements were

53 used to develop and validate an Artificial Neural Network (ANN) model for predicting

54 the corresponding FWD deflection basin (TSD*) from TSD measurements. ELMOD6

55 software was then used to conduct the backcalculation analysis based on TSD and FWD

56 measurements. Evaluation and validation of the proposed methodology was conducted

57 by comparing the critical pavement responses and structural health conditions based on

58 the backcalculated moduli from FWD and TSD measurements.

\section{BACKGROUND}

\section{Traffic Speed Deflectometer}

61 The traffic speed deflectometer is a continuous deflection measurement device mounted

62 on an articulated truck that uses a rear axle of $100 \mathrm{kN}(22,000 \mathrm{lbs}$.$) to load the pavement$

63 structure. The operational speed of the device is up to $80 \mathrm{~km} / \mathrm{h}$ (50 mph); the TSD

64 concept is based on the measurement of the deflection velocity rather than the absolute 
65 deflection of the road surface (Flintsch et al. 2013; Rada et al. 2011). The TSD utilizes

66 Doppler lasers to measure the vertical surface deflection velocity at six points along the

67 midline of the rear right dual tires and in front of the axle at 100, 200, 300, 600, 900, and

$681500 \mathrm{~mm}$ (Nasimifar et al. 2016; Zofka et al. 2014). Various testing programs have been

69 conducted recently to evaluate TSD measurements in comparison to the FWD in

70 Australia, Denmark, France, South Africa, UK, and the United States (Kannemeyer et al.

71 2014; Krarup et al. 2006; Soren et al. 2008; Roberts et al. 2014; Sivaneswaran 2014;

72 Katicha and Flintsch 2014).

73 In Denmark, the TSD showed productivity as high as 3,300 $\mathrm{km}$ of the road 74 network in 10 working days. In addition, a methodology was developed to calculate the 75 structure curvature index $\left(\mathrm{SCI}_{300}\right)$ and the maximum deflection under the center of the 76 load (Krarup et al. 2006; Soren et al. 2008). In Australia, the ability of the TSD to 77 distinguish between damaged and sound pavements was demonstrated, and the 78 measurements showed good correlation between the TSD and the FWD center deflection

79 with a coefficient of determination $\left(\mathrm{R}^{2}\right)$ of 0.7 (Roberts et al. 2014). Recent testing 80 programs conducted in the United States found acceptable repeatability of TSD 81 measurements (Sivaneswaran 2014; Katicha and Flintsch 2014). In addition, the TSD 82 was identified along with the RWD as the most promising continuous deflection 83 measurement devices (Flintsch et al. 2013).

\section{Differences between TSD and FWD}

85 In a recent study conducted by Katicha et al., it was concluded that the differences

86 between the TSD and FWD measurements could be significant (Katicha et al. 2013). The

87 effect of surface irregularities on the TSD measurements, the difference in the load 
88 contact area between the two devices, and the difference in materials transferring the load

89 (rubber plate for the FWD and dual-tire assembly for the TSD), are all factors which may

90 have led to the aforementioned differences (Katicha et al. 2013; Rada and Nazarian 91 2011).

\section{3D Move Software}

93 The University of Nevada at Reno (UNR) developed a software for the analysis of 94 pavement structures known as 3D Move (Siddharthan et al. 2000). The software is based 95 on continuum mechanics and utilizes Fourier transformation technique (Fakhri et al. 96 2013). Several studies have been conducted to evaluate the applicability of the software 97 in calculating pavement responses (Siddharthan et al. 1996; Siddharthan et al. 2002,

98 Siddharthan et al. 2002). Recently, the software was adopted by researchers in various 99 applications in the field of pavement analysis and design (Leiva-Villacorta and Timm 100 2013; Sivaneswaran 2014).

\section{Artificial Neural Networks (ANN)}

102 An ANN consists of a genetic flexible training algorithm that learns how to make 103 decisions based on given information (Kim et al. 2014). ANNs provide robust models 104 that can be continuously updated as new data become available. In addition, they can be 105 used in databases with either large or relatively small amount of data (Plati et al. 2015).

106 ANNs' use has increased tremendously in solving complex civil engineering problems in

107 the last three decades (Ceylan et al. 2014). They can be very generic, accurate, and 108 convenient mathematical models with high capability in simulating numerical model 109 components (Karlaftis and Vlahogianni 2011). However, ANN's limitations include the 
110 need for large data set for fitting and validation, they are considered by some researchers

111 as a black box with no explanatory power, and they can be misused when linear

112 regression can be more suited for simpler problems.

\section{DATA DESCRIPTION}

\section{Louisiana}

115 In 2016, a TSD device operated by the Australian Road Research Board (ARRB) was

116 used to measure vertical deflection velocity, horizontal speed of the vehicle, air

117 temperature, and pavement surface temperature in six parishes of District 05 in

118 Louisiana. Measurements were conducted on 13 control sections (each section was

119 approximately 1.5 -mile-long) at 0.01 -mile interval. FWD measurements were

120 simultaneously collected for the same control sections at 0.1-mile interval for the

121 evaluation and comparison with TSD measurements. The difference between the TSD

122 and the FWD sampling rates is due to the fact that TSD measurements are continuous

123 while FWD measurements are discrete.

\section{Minnesota}

125 FWD and TSD measurements were collected at the MnROAD test facility in Minnesota

126 (Sivaneswaran 2014). The surveyed road network consisted of a 3.5-mile (5.6-km)

127 mainline roadway (ML) with 45 sections and with "live traffic" as part of Interstate 94

128 near Albertville, Minnesota. In addition, a 2.5-mile (4-km) closed-loop low volume

129 roadway (LVR) consisting of 28 sections was surveyed; the section lengths were

130 typically about $500 \mathrm{ft} .(150 \mathrm{~m})$. Furthermore, an 18 -mile $(29-\mathrm{km})$ segment in Wright 
131 County was tested. This segment was located about 20 miles $(32 \mathrm{~km})$ from the

132 MnROAD facility and was divided into nine sections.

133 Tested sections varied between flexible pavements, rigid pavements, and composite

134 pavement sections. Yet, the present study focused on the use of TSD measurements in

135 conducting backcalculation analysis of flexible pavements. Therefore, only TSD and

136 FWD data collected on flexible pavements were considered. The flexible pavement test

137 segments in which both FWD and TSD measurements were conducted consisted of 16

138 sections. Table 1 provides the layer thicknesses of the pavement segments analyzed in

139 the study.

\section{METHODOLOGY}

141 Figure 1 presents a general overview of the proposed methodology to utilize TSD

142 measurements in backcalculation analysis. First, the TSD deflection velocity

143 measurements were used to calculate the deflection basins through numerical integration.

144 Then, both TSD and the FWD deflections were shifted to a reference temperature of

$14520^{\circ} \mathrm{C}$. An ANN model with a topology of 9-5-9 was developed to establish a correlation

146 between FWD and TSD deflection basins. Based on this correlation, the corresponding

147 FWD deflection basin (TSD*) was calculated using the corrected TSD deflection basin.

148 TSD* could be regarded as the deflection basin that would have been measured if FWD

149 was used instead of the TSD in the survey process. TSD* obtained from the ANN model

150 was then used to conduct the backcalculation analysis using ELMOD-6 software. For

151 validation purpose, the developed procedure was evaluated by utilizing the

152 backcalculated layer moduli in stress-strain analysis, fatigue life prediction, and structural 153 health motoring. 


\section{Calculation of TSD Deflection Basin}

155 The TSD device measures the pavement surface deflection velocity at six points

156 in front of the rear axle at 100, 200, 300, 600, 900, and $1500 \mathrm{~mm}$. Muller and Roberts

157 developed a methodology, referred to as the Area under the Curve (AUTC), to

158 numerically integrate the deflection velocity measurements and to calculate pavement

159 surface deflections (Muller and Roberts 2013). First, the deflection velocity is divided by

160 the horizontal travel speed of the vehicle to get the deflection slope. Second, the

161 correlation between the deflection slope and the offset distance from the rear axle is

162 plotted. Third, a curve is fitted through the six points assuming the slope at distance 0 is

163 equal to 0 and the slope at a distance of $3500 \mathrm{~mm}$ is equal to 0 . Finally, the deflection

164 basin is produced by incrementally adding up the area under the curve as shown in Figure

165 2. In the present study, the deflection values were calculated at distances of $0,203,305$,

$166457,610,914,1219,1524$, and $1829 \mathrm{~mm}$ from the rear axle, to match the radial offsets of

167 the FWD geophones.

168 The aforementioned method was adopted by Australia and New Zealand for TSD

169 analysis (Muller and Roberts 2013). Developing a multiple parameter model to calculate

170 the TSD deflections from the TSD deflection slopes, would allow more accurate

171 calculation of the TSD deflection basin (Zofka et al. 2014). The current methodology

172 assumes that the pavement deflection at a distance of $3500 \mathrm{~mm}$ to be equal to zero, which

173 may not always be true especially for pavement structures on very soft soils. 


\section{Temperature Correction}

175 The FWD and TSD deflections were corrected to a reference temperature of $20^{\circ} \mathrm{C}$. The

176 Bells equation was used to calculate the pavement temperature at asphalt mid-depth

177 (Lukanen et al. 2000). Kim and Park concluded that no influence of the load level was

178 found on the temperature correction procedure; therefore, their methodology was

179 assumed to be valid for correcting both TSD and FWD measurements. Pavement

180 surface deflections at radial offsets were then corrected using the methodology described

181 in Equations (1) to (3) based on the approach proposed by Kim and Park as follows (Kim

182 and park 2002):

$$
\lambda_{w}=\frac{w_{T 0}}{w_{T}}
$$

185 where,

$186 \mathrm{w}_{\mathrm{T} 0}=$ the deflection corrected to temperature $\mathrm{T}_{0}$;

$187 \mathrm{w}_{\mathrm{T}}=$ the deflection at temperature $\mathrm{T}$; and

$188 \lambda_{\mathrm{w}}=$ the deflection correction factor calculated as follows:

$$
\lambda_{w}=10^{-C\left(H_{a c}\right)\left(T-T_{0}\right)}
$$

191 where,

$192 \quad \mathrm{H}_{\mathrm{ac}}=$ Asphalt Concrete (AC) layer thickness; and

$193 \mathrm{C}=$ Regression constant calculated as follows:

$$
C=-A r+C_{0}
$$

197 where,

$198 \mathrm{r}=$ the radial distance from the center of the load; and

$199 \mathrm{~A}=-5.26 \times 10^{-8}$ for U.S. Central Region; and

$200 \mathrm{C}_{0}=5.80 \times 10^{-5}$ for U.S. Central Region. 


\section{RESULTS AND ANALYSIS}

\section{Artificial Neural Network Model}

204 There are clear differences between TSD and FWD such as in the loading mechanisms

205 and dynamics. Furthermore, backcalculation programs (e.g., Modulus and ELMOD)

206 assume the load to be applied through a circular plate, which is not the case with the

207 TSD. Therefore, the use of the TSD deflection "as is" in a backcalculation software

208 would not be accurate. In the present study, an ANN model was developed to convert the

209 TSD deflection basin to a corresponding FWD deflection basin (TSD*).

210 A multilayered feed-forward ANN using a back-propagation error algorithm was

211 selected with a tan-sigmoid transfer function. The network architecture consisted of three

212 layers; an input layer of 9 neurons; a hidden layer of 5 neurons; and a target layer of 9

213 neurons. The input layer was fed with the TSD deflections at the nine aforementioned

214 radial distances while the target layer was fed with the FWD measurements normalized to

215 a load level of $40 \mathrm{KN}(9,000 \mathrm{lbs}$.), as shown in Figure 3. A total of 1,467 data points

216 were used in the model development phase. The data were divided into $70 \%$ for training,

$21715 \%$ for validation, and $15 \%$ for testing. Training was halted when the validation set

218 error stopped decreasing to avoid overfitting and to increase the generalization ability of

219 the network. The testing data set had no effect on the training so it was used to provide 220 an independent measure of the network performance.

221 The output of the ANN model is the corresponding corrected and normalized at

$22240 \mathrm{kN}$ FWD deflection basin based on the TSD measurements, which were referred to as

223 TSD*. The regression plots of the ANN model for the training, validation, testing, and 
224 overall sets are shown in Figure 4. All data processing was performed off-line using a 225 commercial software package (MATLAB R2013a, The MathWorks, Inc.). Table 2 226 shows the root mean square error (RMSE \%) values at each radial offset, which were 227 calculated as follows:

228 RMSE $=100 * \sqrt{\frac{\sum_{1}^{\mathrm{n}\left[\text { Predicted value }\left(\mathrm{TSD}^{*}\right)-\text { measured value }(\mathrm{FWD})\right]^{2}}}{\mathrm{n}}} / \frac{\sum_{1}^{\mathrm{n}} \text { measured value }}{\mathrm{n}}$

230 An example of the correlation between FWD, TSD, and TSD* deflections (all corrected

231 to $20^{\circ} \mathrm{C}$ ) is presented in Figure 5. As shown in this figure, the ANN model was

232 successful in converting the TSD deflection basin to a corresponding FWD deflection 233 basin.

235 Model Validation

236 The generalization ability of the presented ANN model was tested and validated using 237 measurements obtained from the testing program conducted at MnROAD. TSD data 238 from 16 flexible pavement testing cells were used as inputs to predict TSD* using the 239 proposed ANN model. The resulted TSD* basin values were then compared with the

240 measured FWD deflections. As shown in Figure 6, the model showed acceptable 241 accuracy with a coefficient of determination $\left(\mathrm{R}^{2}\right)$ of 0.9 .

\section{Backcalculation Analysis}

243 The Dynatest software ELMOD 6 was used in this study to perform the backcalculation

244 analysis. The ELMOD 6 program provides three methods for conducting the

245 backcalculation of layer moduli (radius of curvature, deflection basin fit, and finite

246 element based method). For the present study, the deflection basin method was used in 
247 the backcalculation analysis. The iterative analysis procedure was conducted until an

248 RMSE of $2 \%$ or less was achieved.

249 The backcalculation analyses were conducted using the FWD measurements and

250 the TSD* deflection values. These analyses were conducted for the entire experimental

251 data set (i.e., 13 sections tested in Louisiana and 16 tested in Minnesota). Figure 7

252 shows the correlation between the backcalculated moduli using the FWD and the TSD*.

253 As shown in this figure, there was a good agreement between the backcalculated moduli

254 from FWD and TSD deflection measurements. The RMSE was 12.5\%, 13.2\%, and

$25510.2 \%$ for the AC moduli, base moduli, and subgrade moduli, respectively.

256 Evaluation and Validation of the Proposed Backcalculation Methodology

257 The use of the TSD-based backcalculated moduli was evaluated by conducting a 258 comparison with the FWD-based backcalculated moduli in the following pavement

259 analysis applications using the MnROAD testing data:

260 - Calculating critical pavement responses (stress-strain analysis);

261 - Pavement fatigue life prediction; and

262 - Structural health monitoring.

263 Comparison of Critical Pavement Responses

264 To investigate the proposed approach, critical pavement responses were calculated using

265 3D Move software for the 16 road segments tested in Minnesota. These responses

266 included the horizontal tensile strain at the bottom of the AC layer $\left(\varepsilon_{\mathrm{t}}\right)$ and the vertical

267 compressive strain on the top of the subgrade $\left(\varepsilon_{\mathrm{v}}\right)$. These calculations were conducted 
268 using the backcalculated moduli based on FWD measurements and using the

269 backcalculated moduli based on the predicted TSD* values. A static load of $80 \mathrm{KN}$

$270(18,000 \mathrm{lbs}$.) was applied on a single axle dual-tire assembly. While the tire pressure was

271 assumed $689 \mathrm{kPa}(100 \mathrm{psi})$, the contact area was considered circular, and the distance

272 between the two tires, center to center, was assumed $370 \mathrm{~mm}$ (14.57 in.). Critical

273 pavement responses $\left(\varepsilon_{\mathrm{t}}\right.$ and $\left.\varepsilon_{\mathrm{v}}\right)$ were calculated at three radial offsets; under the center of

274 the tire, under the mid-distance between the tires, and under the tire edge in the Y-Z plane

275 as shown in Figure 8. In the $\mathrm{X}-\mathrm{Z}$ plane, $\varepsilon_{\mathrm{t}}$ and $\varepsilon_{\mathrm{v}}$ were calculated under the center of the 276 tire.

277 From the 3D Move analysis, critical pavement responses calculated based on the

278 FWD measurements, showed good correlation with responses calculated based on the 279 predicted TSD* values. Figure 9 presents these correlations for $\varepsilon_{\mathrm{t}}$ at the bottom of the AC

280 layer and for $\varepsilon_{\mathrm{v}}$ on the top of the subgrade, both calculated under the center of the tire.

281 Table 3 summarizes the error and the correlation between the pavement responses 282 obtained from the 3D Move analysis.

283 Comparison of Number of Cycles for Fatigue Failure

284 The calculated tensile strain at the bottom of the AC layer $\left(\varepsilon_{t}\right)$ and the backcalculated AC 285 moduli $\left(\mathrm{E}_{\mathrm{AC}}\right)$ were incorporated in the bottom-up fatigue model adopted in Pavement $\mathrm{ME}$ 286 (NCHRP 2004):

$$
\mathrm{N}_{\mathrm{f}}=\mathrm{K}_{\mathrm{f} 1} C \cdot \mathrm{C}_{\mathrm{H}} \beta_{\mathrm{f} 1}\left(\frac{1}{\varepsilon_{\mathrm{t}}}\right)^{\mathrm{k}_{\mathrm{f} 2} \beta_{\mathrm{f} 2}}\left(\frac{1}{\mathrm{E}_{\mathrm{AC}}}\right)^{\mathrm{k}_{\mathrm{f} 3} \beta_{\mathrm{f3}}}
$$

$$
\mathrm{C}=10^{\mathrm{M}}
$$




$$
\mathrm{M}=4.84\left(\frac{\mathrm{V}_{\mathrm{b}}}{\mathrm{V}_{\mathrm{a}} \mathrm{V}_{\mathrm{b}}}-0.69\right)
$$

$$
C_{H}=\frac{1}{0.000398+\frac{0.003602}{1+e^{11.02-3.49 h a c}}}
$$

296 where,

$297 \quad \mathrm{~N}_{\mathrm{f}}=$ Number of cycles for fatigue failure;

$298 \mathrm{~K}_{\mathrm{f} 1}, \mathrm{~K}_{\mathrm{f} 2}, \mathrm{~K}_{\mathrm{f} 3}=$ Global calibration coefficients $\left(\mathrm{K}_{\mathrm{f} 1}=0.007566, \mathrm{~K}_{\mathrm{f} 2}=3.9492, \mathrm{~K}_{\mathrm{f} 3}=1.281\right)$;

$299 \mathrm{~B}_{\mathrm{f} 1}, \beta_{\mathrm{f} 2}, \beta_{\mathrm{f} 3}=$ Local calibration factors (set to 1.0);

$300 \quad \mathrm{~V}_{\mathrm{b}}=$ Effective binder content by volume (assumed to be $10 \%$ );

$301 \quad \mathrm{~V}_{\mathrm{a}}=$ Air voids after construction (assumed to be 7\%); and

$302 \mathrm{~h}_{\mathrm{ac}}=$ thickness of AC layers.

303

304 Equation (5) was used to calculate the number of cycles for fatigue failure considering 305 the results obtained from FWD measurements and the results from TSD* values. The

306 comparison showed an RMSE of $16.0 \%$ and an $\mathrm{R}^{2}$ of 0.99 . A comparison between $\mathrm{N}_{\mathrm{f}}$

307 based on FWD measurements and TSD* values is shown in Figure 10.

309 A recent study conducted by the authors introduced the Structural Health Index (SHI)

310 calculated based on pavement backcalculated layer moduli (Elbagalati et al. 2016). The

311 SHI was defined based on the estimated loss in SN; it was scaled logistically from zero to

312 100. A sigmodal function was selected to represent the correlation between the loss in

313 SN (\%) and the SHI:

314

315

$$
\mathrm{SHI}=\frac{100}{1+\mathrm{e}^{0.15(\mathrm{SN} \text { loss \%-30) }}}
$$


317 Fitting parameters in the sigmodal model were selected such that pavement sections with

318 loss in SN greater than 50\% would have an SHI value close to zero, and sections with

319 minimal or no loss in SN will have an SHI value near 100. The SHI evaluation and

320 validation demonstrated that it responded realistically to sections in poor and in good

321 structural conditions. More details about the development and validation of the SHI have

322 been presented elsewhere (Elbagalati et al. 2016). In the present study, the SHI was

323 calculated for the MnROAD 16 Road segments based on both FWD measurements and

324 the TSD* values; and the resulting average RMSE was found to be $4.6 \%$. Figure 11

325 presents a comparison between the SHI values for segments tested in the MnROAD

326 Facility. As shown in this figure, both approaches agreed reasonably well in predicting

327 the SHI.

\section{SUMMARY AND CONCLUSIONS}

329 The objective of this study was to develop a methodology to incorporate TSD

330 measurements in the backcalculation analysis of flexible pavements. TSD and FWD

331 measurements were obtained from two testing programs conducted in Louisiana and at

332 the MnROAD facility in Minnesota. These measurements were used to develop and

333 validate an ANN model for predicting FWD deflection basins from TSD measurements.

334 The ANN model showed acceptable accuracy with a coefficient of determination of 0.9

335 in the validation phase. Furthermore, there was a good agreement between the

336 backcalculated moduli from FWD and TSD deflection measurements. The RMSE was

$33712.5 \%, 13.2 \%$, and $10.2 \%$ for the AC moduli, base moduli, and subgrade moduli,

338 respectively. Evaluation and validation of the proposed methodology was successful and 
339 showed that the backcalculated moduli from TSD measurements can be successfully used

340 in pavement analysis and in structural health monitoring with a reasonable level of

341 accuracy.

342 Conducting additional TSD and FWD testing will allow feeding the developed

343 ANN with more data, which will assist in creating a more robust network with greater

344 generalization ability. In addition, testing of pavement sections with various surface

345 conditions will allow a better understanding of the effect of surface irregularities on TSD

346 measurements.

\section{ACKNOWLEDGMENTS}

348 The financial support of the Louisiana Transportation Research Center (LTRC) is greatly

349 appreciated. The contents of this paper do not necessarily reflect the official views or

350 policies of the Louisiana Transportation Research Center. The authors also acknowledge

351 the help of Nadarajah Sivaneswaran from the FHWA Turner-Fairbank Highway Research

352 Center in providing the MnRoad TSD and FWD data.

\section{REFERENCES}

354 Ceylan, H., Bayrak, M., B., and Gopalakrishnan, K. (2014). Neural Networks

355 Applications in Pavement Engineering: A Recent Survey. International Journal of

$356 \quad$ Pavement Research and Technology, 7(6), p.434.

357 Elbagalati, O., Elseifi, M.A., Gaspard, K., and Zhang, Z. (2016). Development of the

358 pavement structural health index based on falling weight deflectometer testing.

359 International Journal of Pavement Engineering, pp. 1-8. 
360 Fakhri, M., Ghanizadeh, A. R., and Dolatalizadeh, M. (2013). Characterizing horizontal 361 response pulse at the bottom of asphalt layer based on viscoelastic 362 analysis. International Journal of Pavement Research and Technology, 6(4), pp. 379$363 \quad 385$.

364 Flintsch, G., Katicha, S., Bryce, J., Ferne, B., Nell, S., and Diefenderfer, B. 365 (2013). Assessment of continuous pavement deflection measuring technologies. No. 366 SHRP 2 Report S2-R06F-RW-1..

367 Goktepe, A. B., Agar, E., and Lav, A. H. Advances in backcalculating the mechanical 368 properties of flexible pavements. (2006). Advances in Engineering Software, Vol. 37, $369 \quad$ No. 7, pp. 421-431.

370 Haider, S.W., Harsini, I., Brink, W.C., Buch, N., and Chatti, K. (2014). Critical Inputs for 371 Pavement Rehabilitation in the Pavement ME. Transportation Research Board 93rd $372 \quad$ Annual Meeting, No. 14-5037.

373 Kannemeyer L, Lategan, W., and Mckellar, A. (2014). Verification of Traffic Speed 374 Deflectometer measurements using Instrumented Pavements in South Africa. 375 Pavement Evaluation Conference 2014.

376 Karlaftis, M., and Vlahogianni, E. (2011). Statistical methods versus neural networks in 377 transportation research: Differences, similarities and some insights. Transportation 378 Research Part C: Emerging Technologies, Vol. 19, No. 3, pp. 387-399.

379 Katicha, S. W., Flintsch, G.W., Ferne, B., and Bryce, J. (2013). Limits of agreement 380 method for comparing TSD and FWD measurements. International Journal of 381 Pavement Engineering, Vol. 15, No. 6, pp. 532-541. 
382 Katicha, S.W. and Flintsch, G.W. (2014). Field Demonstration of the Traffic Speed 383 Deflectometer in New York. Transportation Research Record.

384 Kim, M., Burton, Y.M., Prozzi, J.A., and Murphy, M. (2014). Maintenance and 385 rehabilitation project selection using artificial neural networks. Transportation $386 \quad$ Research Board 93 ${ }^{\text {rd }}$ Annual Meeting, No. 14-3620, 2014.

387 Kim, Y.R., and Park, H. G. (2002). Use of falling weight deflectometer multi-load data 388 for pavement strength estimation. No. FHWA/NC/2002-006.

389 Krarup, J., Rasmussen, S., Aagaard, L., and Hjorth, P.G. (2006). Output from the 390 greenwood traffic speed deflectometer. In Research into Practice: $22^{\text {nd }}$ ARRB $391 \quad$ Conference.

392 Leiva-Villacorta, F., and Timm, D. (2013). Falling Weight Deflectometer Loading Pulse 393 Duration and Its Effect on Predicted Pavement Responses. Transportation Research $394 \quad$ Board 92nd Annual Meeting. No. 13-2171.

395 Lukanen, E. O., Stubstad, R., and Briggs, R. (2000). Temperature predictions and 396 adjustment factors for asphalt pavement. No. FHWA-RD-98-085.

397 Muller, W. B., and Roberts, J. (2013). Revised approach to assessing traffic speed 398 deflectometer data and field validation of deflection bowl predictions. International 399 Journal of Pavement Engineering, Vol. 14, No. 4, pp. 388-402.

400 Nasimifar, M., Thyagarajan, S., Siddharthan, R. V., and Sivaneswaran, N. (2016). Robust 401 Deflection Indices from Traffic-Speed Deflectometer Measurements to Predict 402 Critical Pavement Responses for Network-Level Pavement Management System 

Application. Journal of Transportation Engineering J. Transp. Eng., Vol. 142, No. 3, $404 \quad$ p. 04016004.

405 National Cooperative Highway Research Program (NCHRP). (2004). Guide for 406 Mechanistic-Empirical Design of New and Rehabilitated Structures. NCHRP Report 407

Plati, C., Georgiou, P., and Papavasiliou, V. (2015). Simulating pavement structural 01-37A. Transportation Research Board, Washington, DC.

Rada, G. R., and Nazarian, S. (2011). The state-of-the-technology of moving pavement

412 deflection testing. FHWA Contract No. DTFH61-08-D-00025, Technical Report, 413 Fugro Consultants, Inc. Austin, Texas.

414 Rada, G., Nazarian, S., Daleiden, J., and Yu, T. (2011). Moving Pavement Deflection 415 Testing Devices: State of the Technology and Best Uses. Proc., 8th International 416 Conference on Managing Pavement Assets, Santiago, Chile.

417 Roberts, J., Ai, U., Toole, T., and Martin, T. (2014). Traffic speed deflectometer: data 418 review and lessons learnt. No. AP-T279/14.

419 Saltan, M., and Terzi, S. (2008). Modeling deflection basin using artificial neural 420 networks with cross-validation technique in backcalculating flexible pavement layer 421 moduli. Advances in Engineering Software, Vol. 39, No. 7, pp. 588-592.

422 Siddharthan, R. V., Krishnamenon, N., El-Mously, M., and Sebaaly, P. E. (2002). 423 Investigation of Tire Contact Stress Distributions on Pavement Response. Journal of 424 Transportation Engineering J. Transp. Eng., Vol. 128, No. 2, pp. 136-144. 
425 Siddharthan, R. V., Krishnamenon, N., El-Mously, M., and Sebaaly, P. E. (2002).

426 Validation of a Pavement Response Model Using Full-scale Field Tests. International

427 Journal of Pavement Engineering, Vol. 3, No. 2, pp. 85-93.

428 Siddharthan, R., Yao, J., and Sebaaly, P. E. (1996). Field Verification of Moving Load 429 Model for Pavement Response. Transportation Research Record: Journal of the 430 Transportation Research Board, Vol. 1540, pp. 125-131.

431 Siddharthan, R., Krishnamenon, N. and Sebaaly, P. E. (2000). Finite-Layer Approach to 432 Pavement Response Evaluation. Transportation Research Record: Journal of the 433 Transportation Research Board, Vol. 1709, pp. 43-49.

434 Sivaneswaran N. (2014). Network Level Pavement Structural Evaluation - A Way 435 Forward. National Pavement Evaluation Conference 2014 Blacksburg, Virginia.

436 Soren, R., Lisbeth, A., Susanne, B., and Jorgen, K. (2008). A comparison of two years of 437 network level measurements with the Traffic Speed Deflectometer. Transport 438 Research Arena Europe.

439 Zofka, A., Sudyka, J., Maliszewski, M., Harasim, P., and Sybilski, D. (2014). Alternative 440 Approach for Interpreting Traffic Speed Deflectometer Results. Transportation 441 Research Record: Journal of the Transportation Research Board, Vol. 2457, \pp. 12$442 \quad 18$. 


\section{List of Figures and Tables}

446 TABLE 1. Structural Descriptions of Pavement Segments

447 TABLE 2. RMSE (\%) between FWD and TSD*

448 TABLE 3. Statistics of Predicted Pavement Response

449

450 Fig. 1. General Overview of the Research Methodology

451 Fig. 2 AUTC Method for Calculating TSD Deflections

452 Fig. 3. General Layout of the Artificial Neural Network Model

453 Fig. 4. Regression Plots of the TSD* vs the FWD Deflection

454 Fig. 5. Deflection Basins of the FWD, TSD, and TSD* at Station (0+00) Section 67-08

455 Fig. 6. Validation of the ANN model using MnROAD data

456 Fig. 7. Correlation between Backcalculated Layer Moduli Using FWD Measurements

457 and TSD* for (a) AC Layer (b) Base Layer (c) Subgrade

458 Fig. 8. Selected Locations for Pavement Response Analysis in the Y-Z Plan

459 Fig. 9. Correlation between Pavement Responses calculated under the Center of the Tire

460 Based on FWD Measurements and TSD* (a) \&t (b) $\varepsilon v$

461 Fig. 10. Comparison between Nf Calculated based on FWD and TSD* Deflection

462 Measurements

463 Fig. 11. SHI Comparison for MnROAD Segments 
TABLE 1. Structural Description of Pavement Segments

\begin{tabular}{|c|c|c|c|c|c|}
\hline Site & Route & Segment \# & $\begin{array}{l}\text { AC Thickness } \\
(\mathrm{mm})\end{array}$ & $\begin{array}{l}\text { Base Thickness } \\
(\mathrm{mm})\end{array}$ & $\begin{array}{l}\text { Subbase Thickness } \\
(\mathrm{mm})\end{array}$ \\
\hline Louisiana & LA 34 & 067-08 & 215.9 & 228.6 & - \\
\hline Louisiana & LA 34 & 067-09 & 254.0 & 203.2 & 127.0 \\
\hline Louisiana & LA 33 & $069-03$ & 177.8 & 279.4 & 304.8 \\
\hline Louisiana & US 425 & 071-02 & 215.9 & 215.9 & - \\
\hline Louisiana & LA 143 & $315-02$ & 254.0 & 127.0 & - \\
\hline Louisiana & LA 616 & $324-02$ & 127.0 & 127.0 & - \\
\hline Louisiana & LA 594 & $326-01 \mathrm{~A}$ & 101.6 & 190.5 & - \\
\hline Louisiana & LA 594 & $326-01 \mathrm{~B}$ & 177.8 & 152.4 & 228.6 \\
\hline Louisiana & LA 821 & $831-05$ & 190.5 & 355.6 & - \\
\hline Louisiana & LA 589 & $862-14$ & 38.1 & 177.8 & - \\
\hline Louisiana & LA 582 & $333-03$ & 241.3 & 215.9 & - \\
\hline Louisiana & LA 139 & 038-01 & 241.3 & 304.8 & - \\
\hline Louisiana & $\mathrm{I} 20 \mathrm{~EB}$ & 451-05 & 101.6 & 330.2 & 241.3 \\
\hline MnROAD & ML & $15 \mathrm{ML}$ & 406.4 & 0.0 & - \\
\hline MnROAD & ML & $16 \mathrm{ML}$ & 127.0 & 304.8 & - \\
\hline MnROAD & ML & $17 \mathrm{ML}$ & 127.0 & 304.8 & - \\
\hline MnROAD & ML & $19 \mathrm{ML}$ & 127.0 & 304.8 & - \\
\hline MnROAD & ML & $3 \mathrm{ML}$ & 76.2 & 152.4 & - \\
\hline MnROAD & ML & $4 \mathrm{ML}$ & 76.2 & 152.4 & - \\
\hline MnROAD & ML & $70 \mathrm{ML}$ & 76.2 & 203.2 & - \\
\hline MnROAD & LVR & 24LVR & 76.2 & 101.6 & - \\
\hline MnROAD & LVR & $27 \mathrm{LVR}$ & 101.6 & 152.4 & - \\
\hline MnROAD & LVR & 28LVR & 152.4 & 101.6 & - \\
\hline MnROAD & LVR & 33LVR & 101.6 & 304.8 & - \\
\hline MnROAD & LVR & 34LVR & 101.6 & 304.8 & - \\
\hline MnROAD & LVR & 35 LVR & 101.6 & 304.8 & - \\
\hline MnROAD & LVR & 78LVR & 101.6 & 203.2 & - \\
\hline MnROAD & LVR & 79LVR & 101.6 & 203.2 & - \\
\hline MnROAD & LVR & 86LVR & 127.0 & 101.6 & - \\
\hline
\end{tabular}


TABLE 2. RMSE (\%) between FWD and TSD*

469

470

\begin{tabular}{|l|c|c|c|c|c|c|c|c|c|}
\hline $\begin{array}{l}\text { Offset } \\
\text { Distance, mm }\end{array}$ & 0 & 203.2 & 304.8 & 457.2 & 609.6 & 914.4 & 1219.2 & 1524 & 1828.8 \\
\hline RMSE, \% & 5.4 & 5.1 & 4.9 & 4.7 & 3.8 & 5.3 & 5.3 & 5.3 & 5.2 \\
\hline
\end{tabular}

471

472

473

474

475

476

477

478

479

480

481

482

483

484

485

486

487

488

489

490 
492

\begin{tabular}{|l|c|c|c|c|c|c|}
\cline { 2 - 7 } \multicolumn{1}{c|}{} & \multicolumn{6}{c|}{ Location } \\
\hline Criterion & \multicolumn{2}{c|}{ Tire Center } & \multicolumn{2}{c|}{ Tire Edge } & \multicolumn{2}{c|}{ Between Tires } \\
\hline Response & $\varepsilon_{\mathrm{t}}$ & $\varepsilon_{\mathrm{v}}$ & $\varepsilon_{\mathrm{t}}$ & $\varepsilon_{\mathrm{v}}$ & $\varepsilon_{\mathrm{t}}$ & $\varepsilon_{\mathrm{v}}$ \\
\hline $\mathrm{R}^{2}$ & 0.91 & 0.96 & 0.85 & 0.96 & 0.88 & 0.96 \\
\hline RMSE \% & 13.8 & 5.6 & 18.9 & 5.3 & 19.3 & 5.4 \\
\hline
\end{tabular}

493

494 


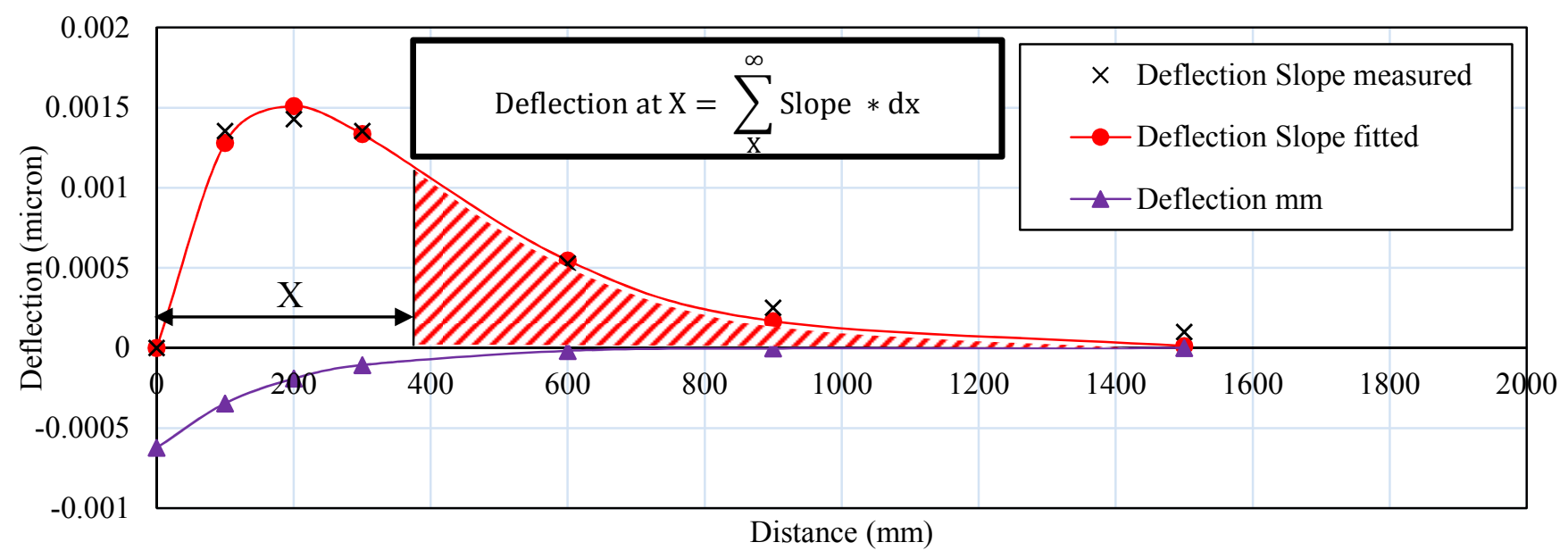




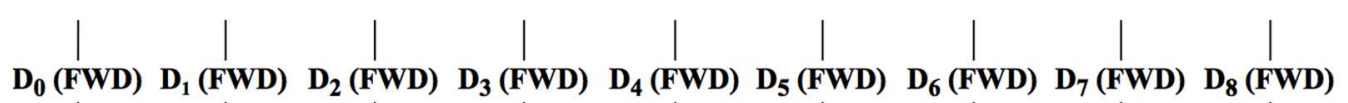

$\mathrm{D}_{0}$ to $\mathrm{D}_{8}$ are deflections at the predefined FWD offsets 

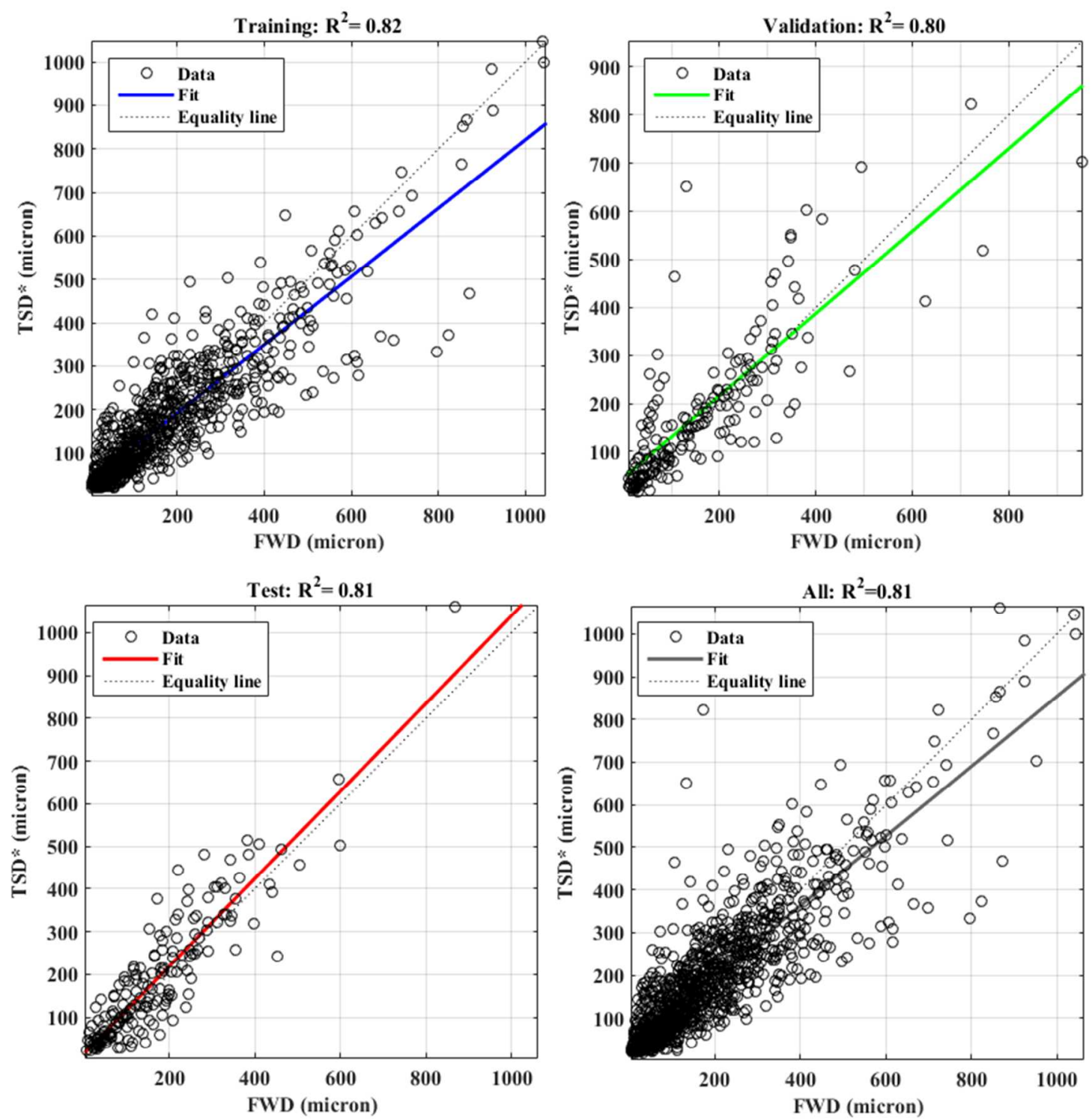


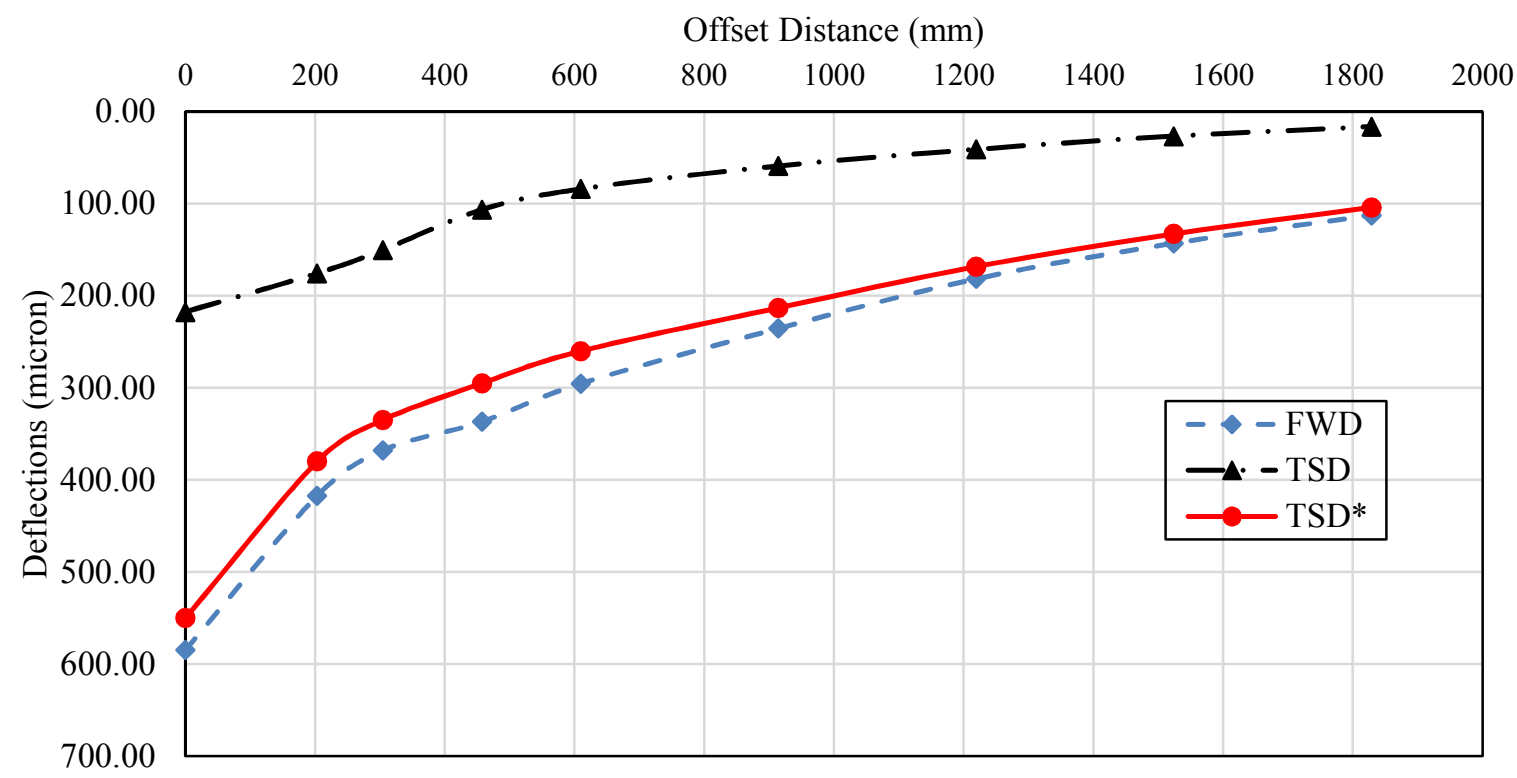

524

Fig. 5. Deflection Basins of the FWD, TSD, and TSD* at Station (0+00) Section 67- 


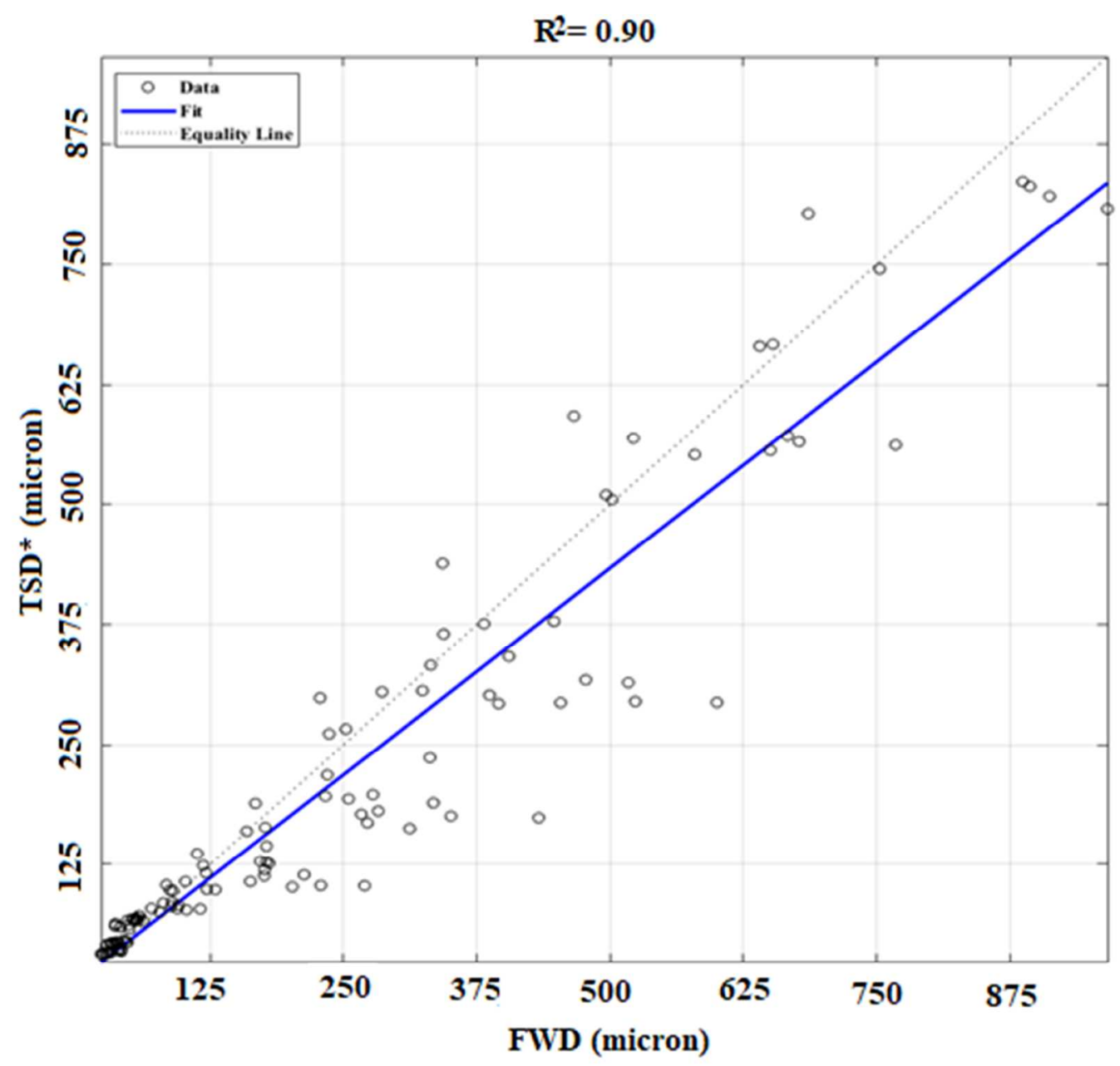

Fig. 6. Validation of the ANN model using MnROAD data 


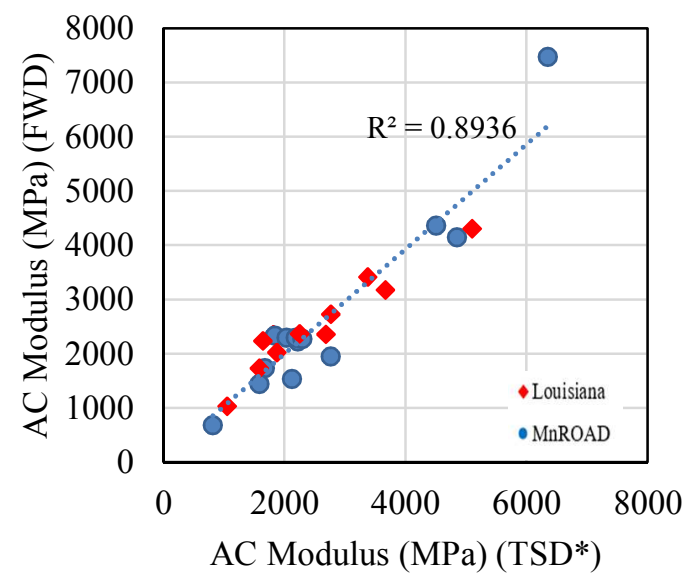

532

533

(a)

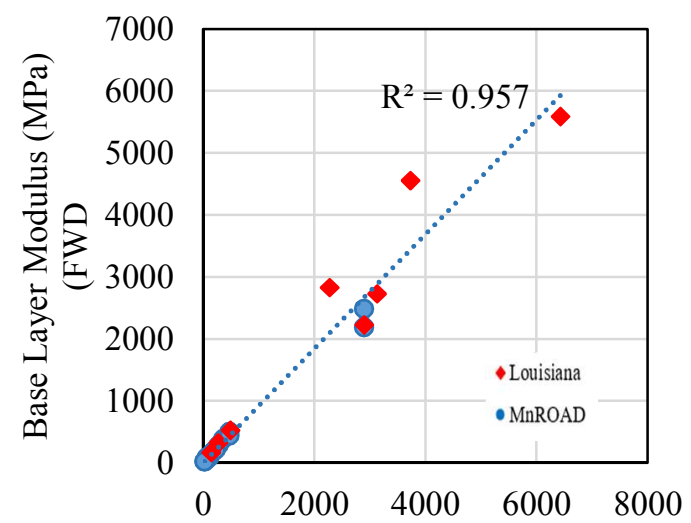

Base Layer Modulus (MPa) (TSD*)

534

535 (b)

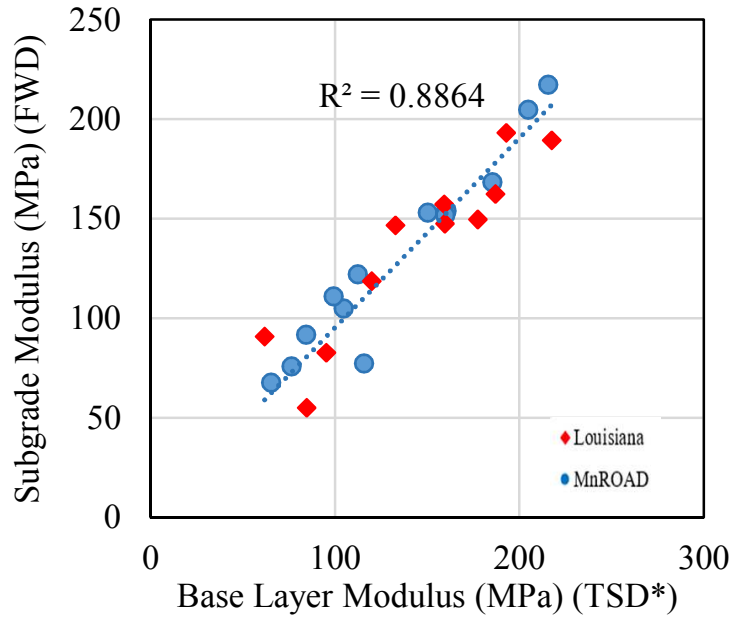

(c) 


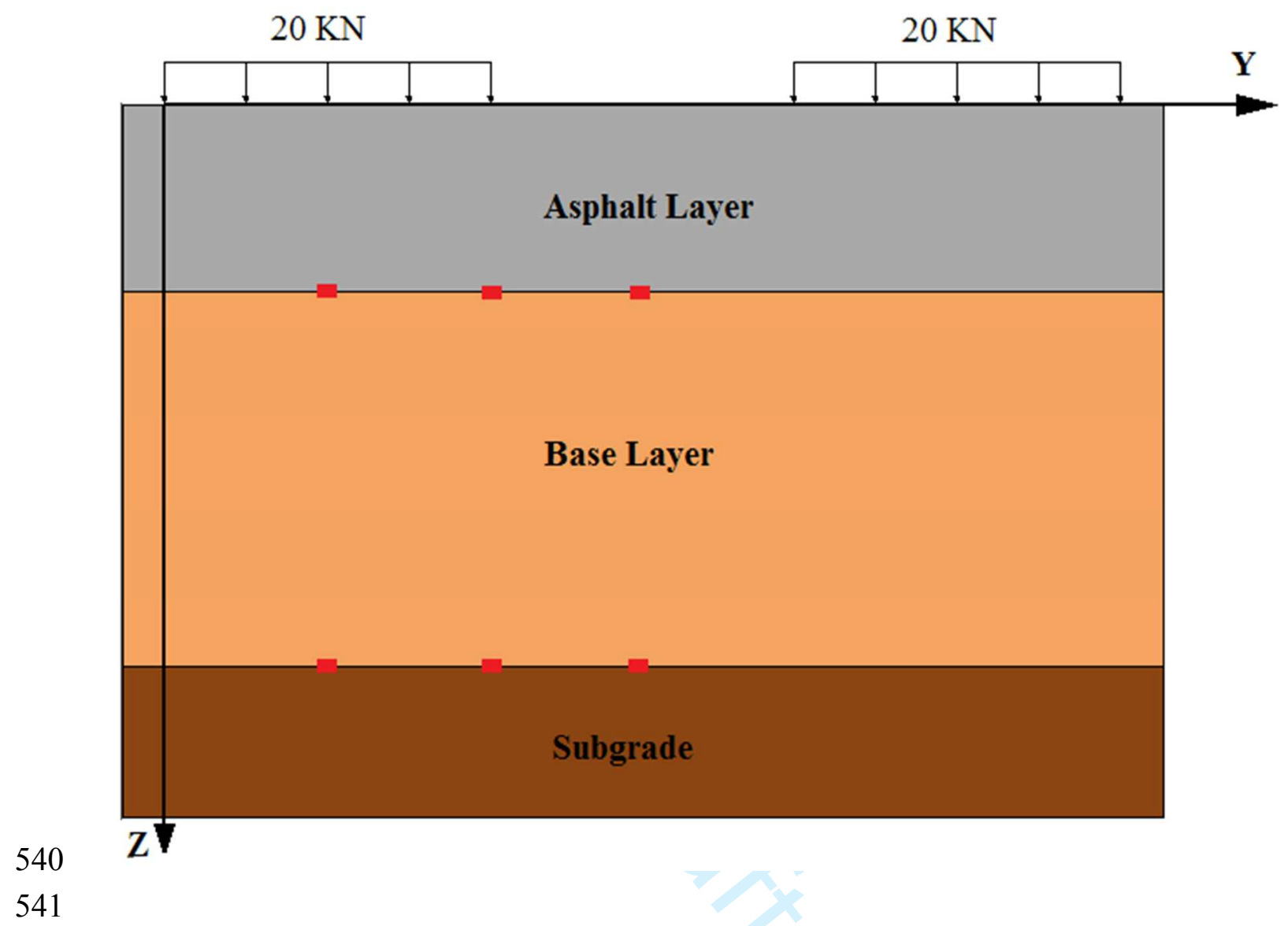




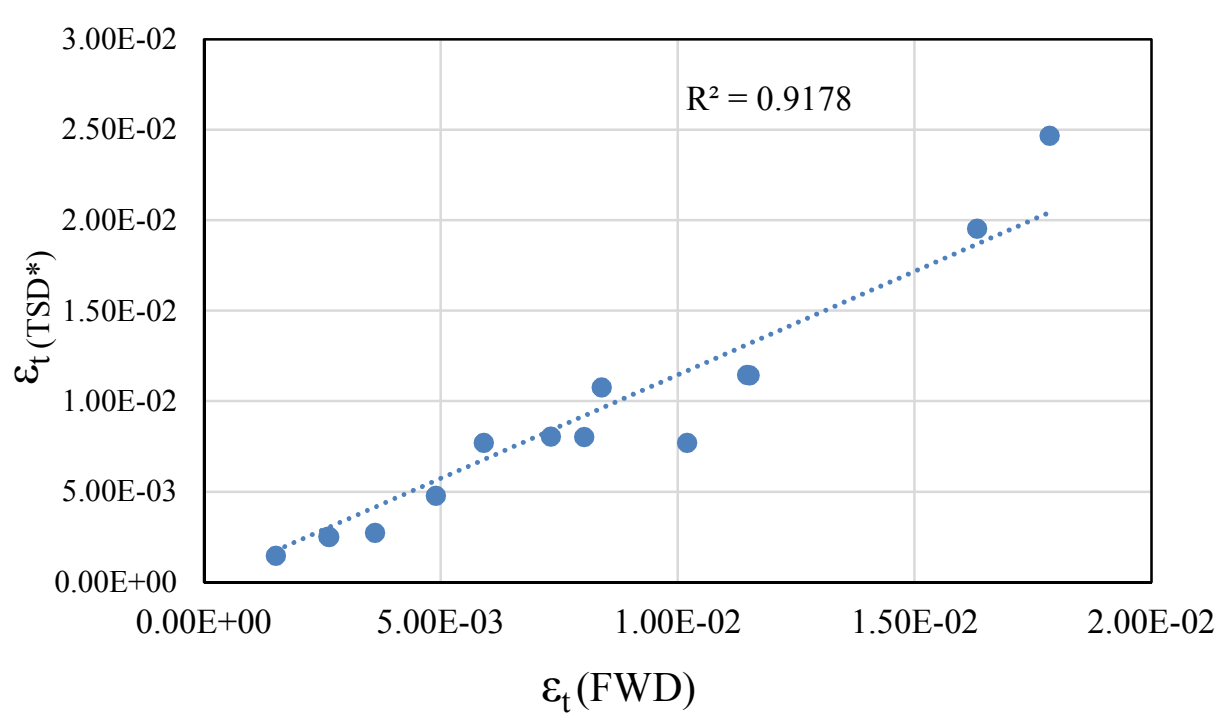

546

547

548

549

550

551

552

553

554 (a)

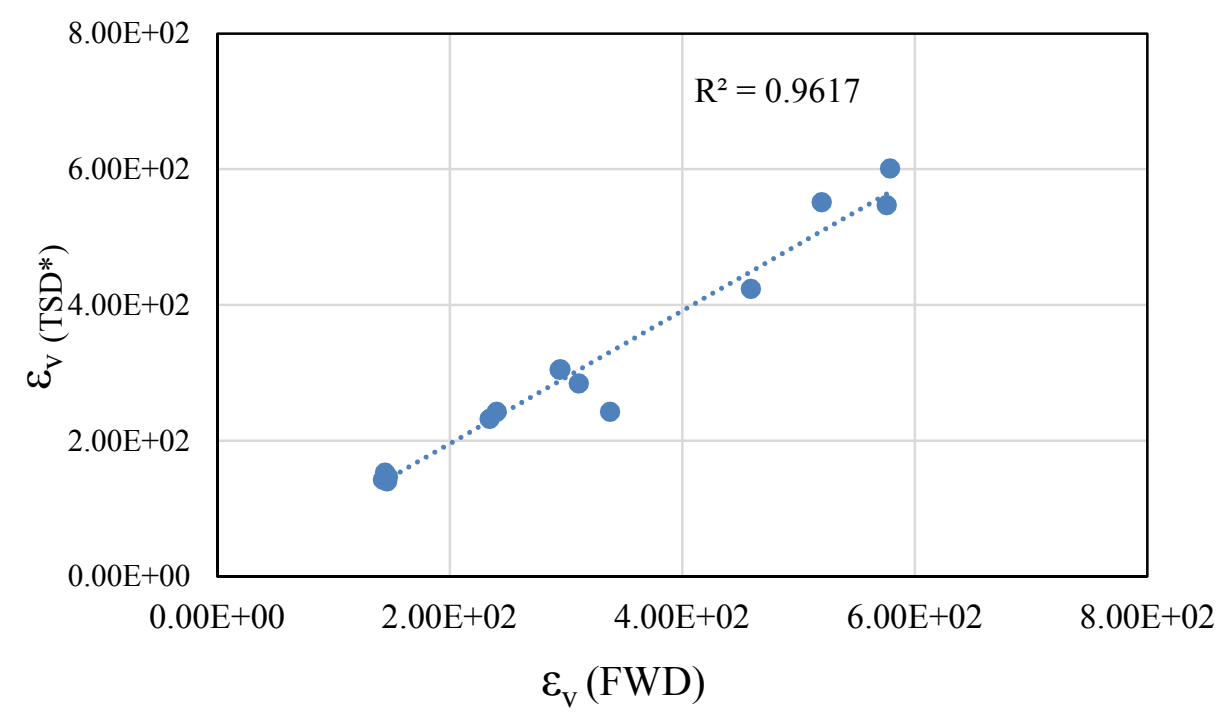

(b)

Fig. 9. Correlation between Pavement Responses calculated under the Center of the Tire Based on FWD Measurements and TSD* (a) $\varepsilon_{\mathrm{t}}(\mathrm{b}) \varepsilon_{\mathrm{v}}$ 


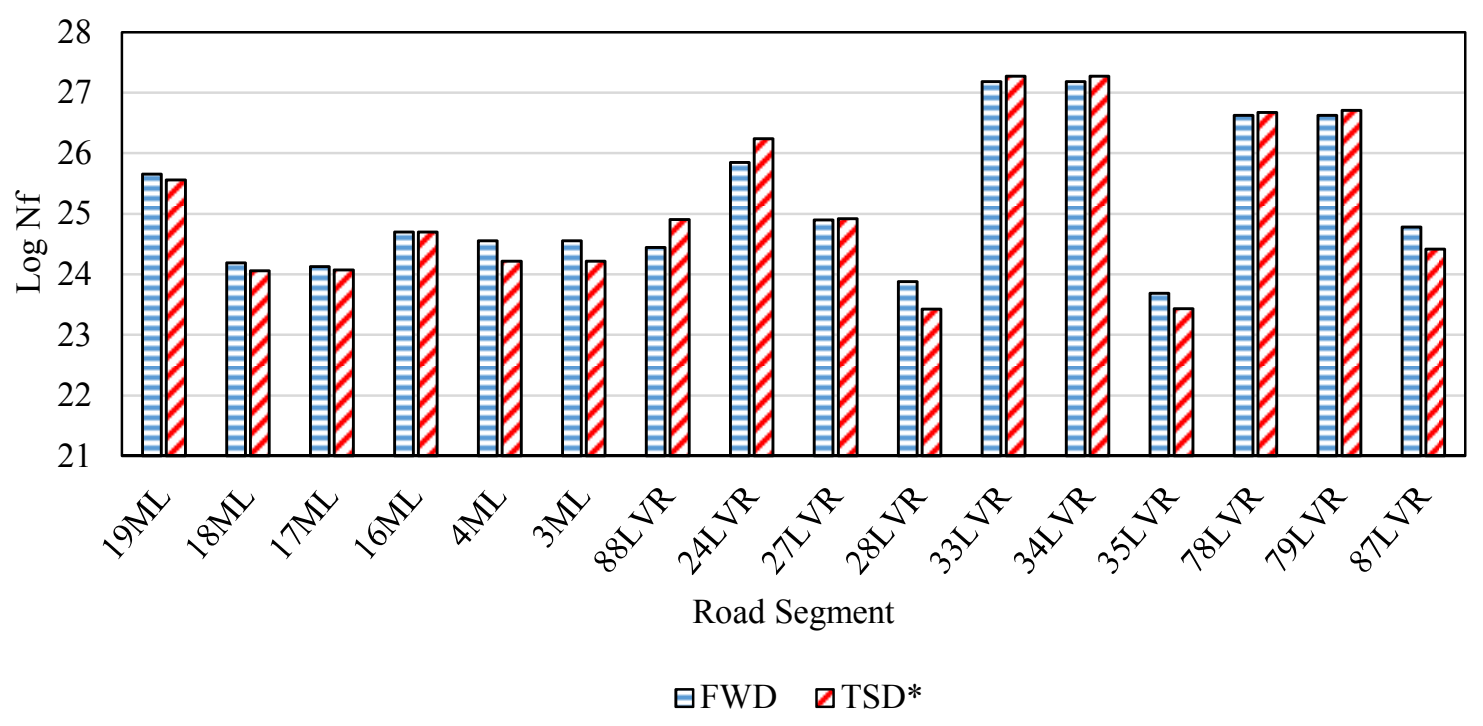
Measurements 


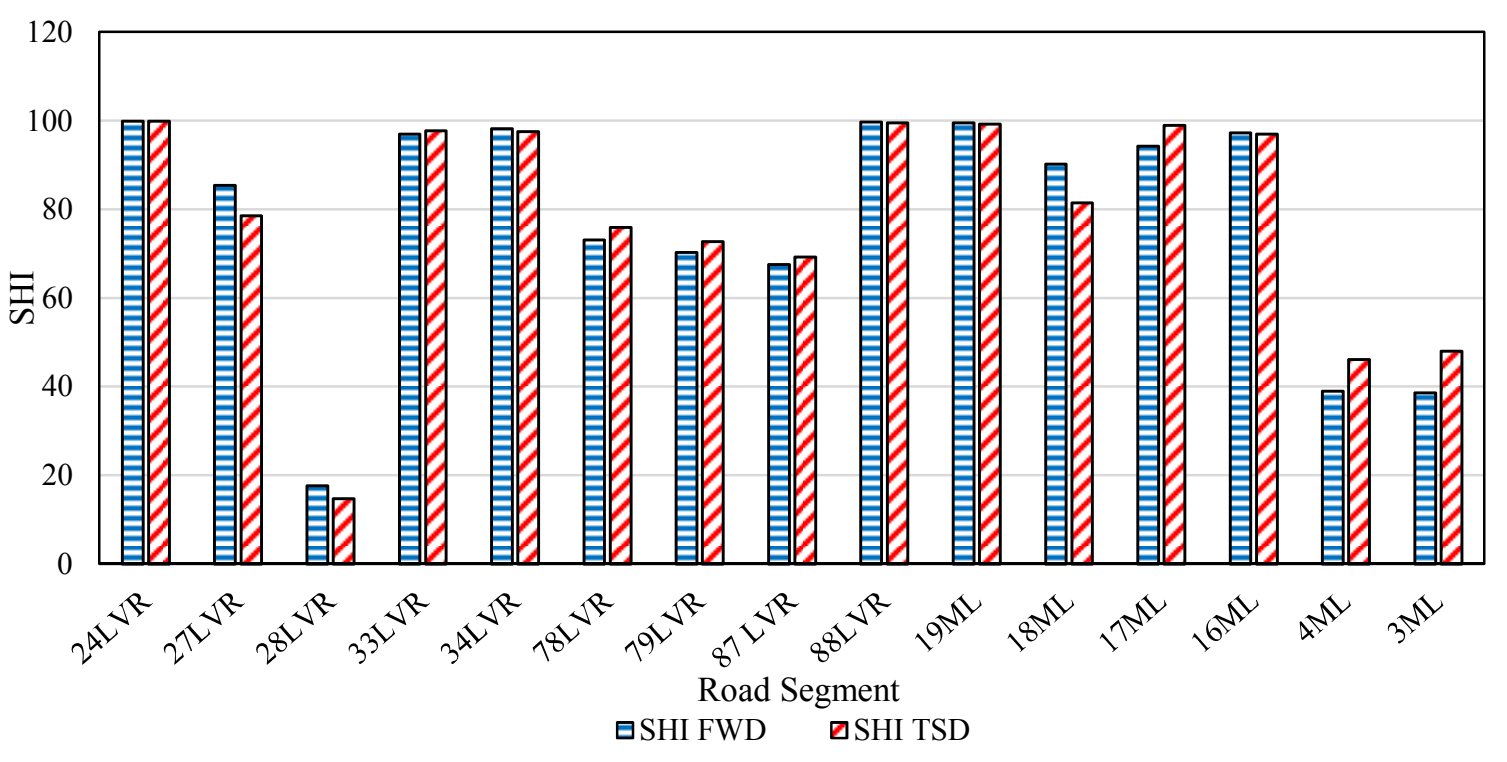

570 